\title{
Board 42: What engineering students think of knowledge in their discipline and how to measure it: An exploratory study
}

\section{Ms. Jinjushang Chen, Florida State University}

My research examines how the concepts of epistemic beliefs of engineering students work together with their academic performance. My current research focuses on refining the measurement of students' epistemic beliefs.

\section{Dr. Jeannine E. Turner, Florida State University}

I am an Associate Professor in Learning and Cognition at Florida State University. My research focuses on understanding the interactions of engineering students' motivation, emotions, beliefs, self-regulation, and achievement.

\section{Min Tang, College of Education, Learning and Cognition Program,Florida State University}

The research interests of mine are: 1) to understand teachers' pedagogical practices and the potential effects of those practices on students' critical thinking and epistemic beliefs in engineering domain, 2) to quantify epistemically-related emotions that occur during the epistemic activity, 3) to explore the best pedagogical practices to improve the efficiency integrating classroom project-based learning and students' real-world problem-solving practice.

I have MS degree from Florida State University in Curriculum and Instruction and BA degree from China Nanchang University in English.

I speak English, Chinese, and some Japanese. I am a proactive person. If you are interested in my research topic, please feel free to contact me via email: mt14n@my.fsu.edu 
What engineering students think of knowledge in their discipline and how to measure it: An exploratory study 


\section{Introduction}

In this research paper, we explain our qualitative approach for examining engineering students' interpretation of domain-specific epistemic-beliefs questionnaire-items. Recently, "engineering epistemologies" emerged as one of the five research areas for the burgeoning discipline of engineering education research. Epistemic beliefs, under this framework, refer to one's beliefs about what knowledge is and what knowing is in the context of engineering disciplines. An understanding and appreciation of epistemology are needed to uncover students' philosophical and psychological divergences towards learning and, thus, can help cultivate students' skills to evaluate and justify their own/others' ideas, opinions, and beliefs. Our past study [1] on engineering students' personal epistemology suggested problems with those quantitative measures in terms of capturing facets of engineering students' epistemic beliefs. Thus, the purpose of this study was to investigate discipline-specific nuances that affect engineering students' interpretation of epistemic-beliefs questionnaire-items to better understand engineering students' epistemic beliefs. To set the stage for our research, we first briefly review existing theories about students' epistemic beliefs. We then explain the current domain-specific assessment of engineering students' beliefs, pointing out problems with current questionnaires.

\section{Literature review}

2.1 The multidimensionality of epistemic beliefs

Personal epistemology has been defined as consisting of multiple sets of beliefs about the nature of knowledge and knowing [2], [3]. The conceptualization of the multidimensionality of personal epistemology enables researchers to quantitatively investigate aspects of this construct and explore how these aspects relate to academic outcomes. In the existing personalepistemology literature, Schommer's Epistemological Questionnaire [2], Wood and Kardash's Epistemological Beliefs [4] and Schraw, Bendixen and Dunke's Epistemic Beliefs Inventory [5], are the three most widely used instruments to measure students' general epistemic beliefs (i.e., domain-general). According to Schommer [2], there are multiple dimensions in the domaingeneral beliefs instrument, each of which serves as a continuum with higher ratings representing naive beliefs and lower ratings representing sophisticated beliefs.

Primarily based on Schommer's [2] work and Perry's [6] theory about the development of personal epistemology, Hofer [3] developed a multidimensional framework that takes into account differences in individuals' beliefs with respect to specific domains of knowledge (i.e., domain specific). These dimensions include: 1) certainty of knowledge - the extent to which individuals believe knowledge is fluid and changing or static and unchanging; (2) simplicity of knowledge - the extent to which individuals believe knowledge involves highly interrelated concepts or is comprised of unrelated, simple constructs; (3) source of knowledge - the extent to which individuals believe knowledge is transmitted by authority or they should construct their own knowledge; and (4) justification for knowing — reasons individuals have for integrating information as justified knowledge. Using this framework of epistemic beliefs, Hofer [3] then developed the Discipline-focused Epistemological Beliefs Questionnaire (DFEBQ). During the validation process of the survey items, she added one more dimension: (5) attainability of truth - the extent to which individuals believe in the capacity of humans to obtain 'truth.'

Respondents are asked to think of one specific domain/discipline when answering the items in the 5-point Likert questionnaire. All of the subscales include a continuum with one end 
suggesting naïve and less constructivist views and the other end suggesting sophisticated and more constructivist views.

\subsection{Psychometric issues in current instruments}

Hofer's Discipline-focused Epistemological Beliefs Questionnaire [3] and White and his colleagues' Epistemological Beliefs Assessment for Physical Science [7], have been used to assess students' epistemic beliefs within a specific discipline. No matter which instrument researchers have adopted, measures of the multidimensional framework have been problematic in terms of validity and reliability. For example, some of the theoretical factors were not identified in some studies [8], [9], and some researchers have found the factor structures are hard to duplicate in replicated studies [10].

Therefore, existing instruments may be inadequate to capture the representations of engineering students' domain-specific epistemic beliefs. The first explanation of these assessment-issues is the predefined meanings within the questionnaires [11]. Although one may argue that the theorized meanings reflect the overarching framework of key components of epistemic beliefs, prior research has shown that people in different domains vary in their interpretations of the statements that represent those meanings [12]. As such, students' responses to the items with the predefined meanings may not reflect their own ideas or proximal beliefs [11]. Additionally, current surveys assume ratings of statements assess students' epistemic beliefs along a continuum. The lower and higher end of the continuum represent two opposing stances towards one statement. Greene and $\mathrm{Yu}$ [13] have stated that a low rating on a belief-item may not necessarily mean the person possesses an opposing view of the higher rating of the belief-statement. Another suggested limitation [13] is the use of a center point in Likert-type scale labeled "neither agree nor disagree." This center point may not be part of the continuum from strongly disagree to strongly agree, and when students choose this option, interpretation is difficult. For example, in a statement about where the source of knowledge should reside, one end of the ratings represent knowledge is transmitted by experts - and the other end of the ratings represent - knowledge should be constructed by myself. Does the mid-point mean a mix of the two beliefs, a possession of conflicting representations, or an equivalent of "I'm not sure?"

In addition to the problems just mentioned, the inconsistency and unstableness of the instruments in existing studies may be an indication of possible incoherence in students' beliefs across contexts [11]. For example, there is a growing body of studies showing that students may hold inconsistent epistemological beliefs of science in different contexts [14], [15]. The possibility of the unstable nature of epistemic beliefs explain the difficulty of assessing engineering students' domain-specific epistemic beliefs. Because individuals' domain-specific beliefs are more sensitive to a context, the representations of their epistemic beliefs about a specific discipline may be stored with corresponding contextual information, while their domaingeneral epistemic beliefs represent more general representations without context.

Finally, most of the domain-specific instruments used today were adapted from versions of domain-general instruments. Domain-specific items in one context may not translate well into another context. Thus, it's hard for current domain-specific beliefs instruments to truly reflect engineering students' domain-specific thinking due to lack of, or insufficiency of, domain- 
related contextual information represented within the items. As Greene and $\mathrm{Yu}$ [13] suggested, students' relevant beliefs about the nature of knowledge and knowing are, themselves, domainspecific. Therefore, creating domain-specific items should target students' beliefs within specific contexts. Researchers need to develop items that are specific to the discipline so that respondents can activate the corresponding epistemic beliefs that are aligned with researchers' understandings and expectations. Otherwise, students' responses to items and researchers' interpretation of their ratings will not have shared meanings.

Unfortunately, Hofer's widely used self-report instrument, the Discipline-Focused Epistemological Beliefs Questionnaire (DFEBQ) [3], suffers the same psychometric problems described above. Prior studies [1], [9] suggested that the DFEBQ may be inaccurate and inconsistent, especially in the context of engineering-education settings. The measure of DFEBQ fails to capture the facets of epistemic beliefs in the population of engineering students. Therefore, more research should be done to examine closely what aspects of this measure are problematic in order to make recommendations for further development of new items targeting students' beliefs within the field of engineering. Our study answers this need by exploring the cognitive validity of items, under Hofer's theoretical framework. In the current study, we adopted the technique of cognitive interviewing recommended by Karabenick and his colleagues [16]. With this approach, we examined how well respondents' interpretation of the items agreed with the researchers' intended meaning.

\subsection{Cognitive interview approach}

The purpose of the cognitive interview approach is to provide an additional method to evaluate the validity of developed surveys. The intent is to beyond traditional types of measurement validity, such as content, criterion, and construct validity [17] to better inform instrument development. Cognitive validity refers to the degree to which respondents in a certain population interpret items in a similar way to what researchers intended. As Karabenick et al. [16] proposed, based on information processing theories, there are three critical points at which researchers can use respondents' articulation of thoughts to assess the validity of an item - item interpretation, elicited memory of the information, and justification of the response option. During the interview, interviewers should first probe respondents for item interpretation. Item interpretation is considered acceptable if items are interpreted by respondents as researchers intended the items to be interpreted. Secondly, for coherent elaborations, interviewers ask questions to evaluate whether respondents elicit related memories of their experiences or beliefs. In the last step, interviewers target questions about whether respondents provide a consistent response option to their previous elaborations. Obtaining these three pieces of information provides evidence to assess whether individuals' thinking is congruent with the item's intended meaning. According to Karabenick et al. [16], evaluating cognitive validity of the data should ensure the following steps: "(1) clearly identify the validity coding criteria that operationalizes the intended meanings; (2) conduct semi-structured interviews with targeted populations; (3) apply coding criteria to interview transcripts to quantify item-validity; (4) analyze validity, and establish inter-rater reliability, and (5) modify items or make recommendations for modification based on validity performance" [12]. 
3. Method

3.1 Participants and procedures

Fifteen undergraduate engineering students (11 males, 4 females) participated in the study. All of the students were recruited from an engineering program in the southeast. Students are admitted to the program when they reach their third year in college. The participants in this study are from five categories of engineering majors: mechanical, civil, chemical/biomedical, electrical, industrial/manufacturing engineering. We interviewed three participants from each engineering category. Guest and his colleagues [18] suggested that 12 interviews of a homogenous group should be enough to provide thick and rich data for rigor and trustworthiness. Our target population was relatively homogenous; we interviewed 15 participants from five engineering majors ( 3 from each major).

Before the interview session, participants first completed a shortened version (six items) of DFEBQ [3] with respect to the domain of engineering. The measure used a five-point Likert scale, with ratings from 1 (strongly disagree) to 5 (strongly agree). Lower scores on this scale represent less constructivist views, higher scores suggest more constructivist views. During the interview session, participants were asked questions about their interpretation of each item, their personal experience and opinions related to each item, and their explanation of the answer-choice for each item. To elicit participants' responses, the interviewer used a semi-structured protocol with a mix of open-ended questions such as "Can you explain why you chose strongly disagree?" and structured questions such as "Did you have a specific example in your mind when responding to this item?" The interviewer reminded participants of the domain-focus of the items when necessary (e.g., "Is that specific to your discipline or applicable in general?"). All of the interview sessions were recorded and transcribed for later data analysis.

\subsection{Materials}

The items were selected based on the evidence from our prior study [1] conducted with the same population as well as Hofer's [3] scale validation study. The results of a prior study [1] showed that only three dimensions of the DFEBQ were achieved with engineering students, a similar problem found in other studies [3], [9]. For this study, we chose one or two representative items from each subscale that demonstrated problems in prior research. For example, we chose the item, Ideas are really complex (Item 10), from the Simplicity of Knowledge subscale because both Hofer and our previous study failed to identify the subscale. We also chose the item, Answers to questions in this field change as experts gather more information (Item 23), from the Certainty of Knowledge subscale, because it did not have a high loading in our previous study, but had a high loading in Hofer's factorial report. Two items from the subscale Source of Knowledge were chosen because the entire subscale was not identified in our previous study and, in Hofer's validation study yielded a low Cronbach's alpha $(\alpha=.55$ in psychology and $\alpha=.60$ in science). These two items were: Sometimes you just have to accept answers from the experts in this field, even if you don't understand them (Item 3), and I am most confident that I know something when I know what the experts think (Item 26). We chose the item, Correct answers in this field are more a matter of opinion than fact (Item 12), from the Justification of Knowing subscale because it was not identified in our previous study as fitting with the factor and loaded low in Hofer's factorial analysis. Finally, we chose the item, Experts in this field can ultimately get to the truth (Item 17), from the Attainability of Truth subscale that both Hofer and our prior research identified as a coherent subscale and had high loadings. 


\subsection{Coding process}

For the coding procedure, we developed a coding guide similar to the one developed by Muis and his colleague [12]. We rated each student's response for acceptability, i.e., acceptable, partially acceptable, or not at all acceptable (a rating of 2,1 , or 0 , respectively) for (1) item interpretation, (2) congruent elaboration (i.e., elicited memory), and (3) coherent choice. Iteminterpretation was considered valid if the student provided an explanation of the item that aligned to its intended meaning. For congruent elaboration, to receive a rating of 2, students' responses had to mention a related field or discipline, and their experiences or examples had to be related to the item's intent. Finally, for coherent response choice, students' option made on the Likert scale had to be coherent with their elaboration. We used Muis et al.'s [12] definitions and range of acceptable beliefs (See Table 1) to guide our data analysis. We rated the cognitive validity score for the three sections first and then summed the scores to obtain a global validity score for each item. Based on the coding principles and criteria, two trained raters independently rated each student's responses of the items in terms of all three aspects of cognitive validity. We also allowed additional codes to emerge and group them into new emergent themes during analyses [19]. Segments from the transcripts that were relevant to the coding themes were marked and the remainder of the responses were removed from analyses. The inter-rater reliability established $83 \%$ of agreement in this study. Disagreements were discussed and resolved.

\section{Results}

The following sections provide both quantitative and qualitative results from the cognitive interviews with the engineering students. We report the results about the cognitive validity and new themes in terms of each item. Overall, as can be seen from Table 2, participants' interpretation of all of the selected items approached an acceptable level, ranging from 1 to 1.67. Their coherent elaboration scores of the items also demonstrated an acceptable range (1.2 1.57), expect for the item under the subscale of Simplicity of Knowledge, which was below the acceptable rating of 1 . The average score of the coherent responses approached acceptable levels as well $(1.27 \sim 1.83)$. The item of Simplicity of Knowledge had the lowest scores across the three aspects of cognitive validity.

Source of Knowledge Item 1. When interpreting the item "Sometimes you just have to accept answers from the experts in this field, even if you don't understand them," four of the participants talked about trusting the professors during their teaching. For example, students explained: "I trust when they're teaching. That's what it is. I just need to figure it out," "You have to trust your professors, I mean I hope that they're telling you the right stuff because usually they've been teaching for a long time." Most of the students elicited the memories about contexts where they had a class with their professors teaching new content to them. When they elaborated their choices to the item, students who chose a rating of four instead of five (somewhat agree versus strongly agree) talked about their reservations about the statement. For example, one student said that although "there's a lot of times when an equation is just fed to us," he viewed this as "taking it at face value" and wanted to "do further research and to see whether [I] think that's justifiable or not." Some students chose the center, neutral, option because, while they trusted the answers given by experts were right, they wanted to understand them, or believed they eventually would understand them on their own. 
Table 1 Researchers' definitions and range of acceptable answers for each of the dimensions

\begin{tabular}{|c|c|c|}
\hline Category & Definition & Range of Beliefs \\
\hline Certainty & $\begin{array}{l}\text { Certainty is the degree to which } \\
\text { knowledge is more fixed versus more } \\
\text { fluid. }\end{array}$ & $\begin{array}{l}\text { Fixed - Knowledge cannot be doubted. Everyone } \\
\text { would come up with the same answer to a question and } \\
\text { the answer to a question will probably never change. } \\
\text { Fluid-Knowledge is not certain. Answers to questions } \\
\text { are the best we know now but knowledge evolves as } \\
\text { more information is gathered. }\end{array}$ \\
\hline Simplicity & $\begin{array}{l}\text { Simplicity is the degree to which } \\
\text { knowledge is more a set of facts versus } \\
\text { more a network of highly interrelated } \\
\text { concepts. }\end{array}$ & $\begin{array}{l}\text { Set of facts - Knowledge is one fact after another and } \\
\text { facts are unrelated. Answers are straightforward. } \\
\text { Highly interrelated concepts - Knowledge is } \\
\text { interconnected concepts. The meaning of one concept } \\
\text { is complex, relative to others, and depends on the } \\
\text { situation where the concept is used. }\end{array}$ \\
\hline Source & $\begin{array}{l}\text { Source focuses on whether people } \\
\text { acquire knowledge from outside the self } \\
\text { versus by actively constructing it within } \\
\text { the self. }\end{array}$ & $\begin{array}{l}\text { Outside the self-people believe knowledge is handed } \\
\text { down by an authority (like a teacher or expert) and } \\
\text { should not be questioned. } \\
\text { Within the self - people believe they can construct } \\
\text { knowledge by interacting with others, and using logic } \\
\text { and/or evidence provided by experience. }\end{array}$ \\
\hline Justification & $\begin{array}{l}\text { Justification focuses on how claims } \\
\text { become accepted as knowledge by } \\
\text { relying more on authority and experts } \\
\text { versus relying more on personal } \\
\text { experience and evaluation. }\end{array}$ & $\begin{array}{l}\text { Relying on authority and experts - people accept } \\
\text { claims made by experts if experts reach consensus or } \\
\text { agreement. } \\
\text { Relying on personal experience and evaluation - } \\
\text { people question experts, and evaluate information } \\
\text { based on logic and/or evidence provided by experience. }\end{array}$ \\
\hline $\begin{array}{l}\text { Attainability } \\
\text { of Truth }\end{array}$ & $\begin{array}{l}\text { Attainability of Truth concerns the } \\
\text { degree to which an individual believes } \\
\text { that ultimate truth is obtainable versus } \\
\text { unobtainable. }\end{array}$ & $\begin{array}{l}\text { Obtainable - people believe it is possible to ultimately } \\
\text { figure out the correct answer to any question and that } \\
\text { there is a solution to every problem. } \\
\text { Unobtainable means people believe that some things } \\
\text { will never be known and some problems have no } \\
\text { solution. }\end{array}$ \\
\hline
\end{tabular}

Table 2 Mean cognitive validity scores by items

\begin{tabular}{lllll}
\hline & $\begin{array}{l}\text { Item } \\
\text { Interpretation }\end{array}$ & $\begin{array}{l}\text { a } \\
\text { Related } \\
\text { Elaboration }^{\text {a }}\end{array}$ & $\begin{array}{l}\text { Coherent } \\
\text { Response }^{\text {a }}\end{array}$ & $\begin{array}{l}\text { Global Sum } \\
\text { Score }^{\mathrm{b}}\end{array}$ \\
\hline Source of Knowledge & 1.17 & 1.2 & 1.5 & 3.87 \\
Source of Knowledge 2 & 1.67 & 1.6 & 1.6 & 4.87 \\
Justification for Knowing & 1.3 & 1.43 & 1.83 & 4.57 \\
Simplicity of Knowledge & 1 & 0.83 & 1.27 & 3.1 \\
Certainty of Knowledge & 1.67 & 1.57 & 1.57 & 4.8 \\
Attainability of Truth & 1.6 & 1.33 & 1.47 & 4.4 \\
\hline Average of all items & 1.40 & 1.33 & 1.54 & 4.27 \\
\hline
\end{tabular}

\footnotetext{
${ }^{a}$ Possible range of $0-2$

${ }^{\mathrm{b}}$ Possible range of $0-6$
} 
Source of Knowledge Item 2. With respect to the item: I am most confident that I know particular item a "weird one" or a "strange thing" to interpret in the field of engineering. They thought that whether or not they were confident about knowing something was irrelevant to what the experts thought. One student offered: "I don't think that I'm confident when I know what [experts] think [because] I'm confident in things that I know because I know those things."

When talking about experts, some students gave examples of professors in their department; one student viewed the grades of exams or assignments as the opinions from experts, other students elicited memories of experts, in general, who know more than they do within the field of engineering. Thirteen of the fifteen participants chose "neutral" or "somewhat agree" for this item and their elaboration of their choices were not necessary aligned with the theory's purported meaning. Some students thought knowing experts' opinion and having their own judgement were both important. Some students chose neutral because "it depends which experts we're talking about." One student stated, "I'll have ... to see [what] multiple experts say to judge that, and [then] see what the actual, real things are, and then, make a decision." Another student explained, "I don't really want to trust the new experts completely." One student said his reason to provide a neutral rating was that, even if he knew what the experts were talking about, "it doesn't mean I know the subject as a whole." One student explained his reason for a neutral response was more of a reflection of his own lack of confidence: "I have a hard time trusting myself even when I know the right answer. Sometimes I'm still hold things back, trying to find out what everyone else thinks about a situation before I decide anything." Interestingly, this student's statement seems to point to a reliance on "others" to form his own opinion, thus relying on others' expertise.

Justification for Knowledge. With respect to the item, Correct answers in this field are more a matter of opinion than fact, most of the students disputed the statement when interpreting the item. They treated an opinion within engineering as representing "bias," which they believed could be dangerous in some engineering disciplines. In their elaboration of the item, they mentioned "data analysis," "experiment" or "building a bridge/building/signal" to explain/justify their answer. Students were highly focused on elaborating the importance of facts and having the right answer in their field. Most of the students held the belief that knowledge in the field was not "subjective" but rather "objective." Some students stated that answers to questions in the field of engineering were going to be "either wrong or right." One student explained, "in electrical engineering it's not really opinion, because there's only maybe one or two ways to solve [a problem], you always get the same answer."

Simplicity of Knowledge. Students' interpretation of the item, Ideas in this subject are really complex, demonstrated wide-ranged variations that deviated from the theory's defined meaning. "Complex" in researchers' definition describes knowledge that involves highly interconnected concepts and complicated structures. Most students interpreted complexity of knowledge as hard to grasp during the learning process. Some students agreed or disagreed with the statement because they thought that whether ideas were complex or not depended on how familiar they were with the content. For example, to explain the choice of a neutral rating, one student stated, "[the class] Intro to Environmental Engineering is new and it's complex for me" and another student said, "I just don't have the knowledge of [specific content] now, but I'm confident in my abilities to understand it." One student interpreted the item from a social 
perspective. He chose neutral because, for him, he had been involved in relevant engineering courses since middle school, so ideas in engineering didn't seem complex; but, to people who had not been exposed to relevant education, knowledge in engineering fields would seem complex. Another student viewed the complexity of knowledge in an incremental way. He explained, "I bet a couple hundred years ago, they thought they knew pretty much everything. But now, even basic freshman classes are like what the smartest people [knew] in the world a hundred years ago. So, I [think knowledge] is pretty complex and it continues to keep getting more and more complex."

Certainty of Knowledge. Thirteen of the fifteen participants agreed with the statement, Answers to questions in this field change as experts gather more information; although most students elaborated on the previous item of related to Justification for Knowing that correct answers in their field were built upon facts and they had to make sure that the solution was "one hundred percent correct." Students interpreted knowledge in this item as "new materials," "new technology," "new methods," or "the way we apply" formulas or laws. Their responses to this item did not refer to knowledge as a specific solution to a question as they did for the item of Justification for Knowing. Some students were aware that there was some part of knowledge was relatively fixed such as "speed of light" and "gravity on earth," while other parts of knowledge kept changing as people gathered more information. But overall, they chose to pick the stance that knowledge was evolving in their field, and only two of the students chose a neutral stance due to their awareness of conflicted beliefs of knowledge in engineering. An interesting finding was that, even in his elaboration one student said that, in his major of civil engineering, knowledge was stable. He explained, "like, you can look into different equations, but it's all going to lead back to the same [answer]." On the other hand, another student chose a neutralstance because he believed that knowledge should be changing if he was in other disciplines.

Attainability of Truth. When talking about whether, Experts in this field can ultimately get to the truth, students had reasonable interpretations of this item. As they further elaborated their experiences or examples related to the item, most of them talked about how they or experts got to truth. For example, one student made an example of Maxwell, saying, "he got a lot of raw data from, uh - I forget exactly what history it is — but he just spent a lot of time with this data, and eventually he came up with a bunch of equations." Based on their elaboration of the option, most of the students were pretty coherent in their beliefs that truth was attainability in their field. Two students chose neutral because they connected with their beliefs about the certainty of knowledge; they believed there was never "a truly right answer."

\section{Discussion}

Overall, students provided acceptable interpretations for the items except for the item under the subscale of Simplicity of Knowledge. Muis et al. [12] have identified the same problem with items of this subscale. They suggested that students interprete a "complex idea" as something hard to understand, not necessarily complex per se. In this study, engineering students demonstrated more variations of the interpretations of this item that deviated from the theory's purported meaning. In order to better assess the subscale Simplicity of Knowledge, more precisely phrased items should be constructed that have more specific words to describe the characteristics of engineering fields. Moreover, all of the ratings with respect to cognitive validity in this study were lower than those in Muis et al.'s [12] study, despite our study using 
the same coding criteria. This could be due to larger variation of engineering students' understanding of these belief-items compared to students in other domains that were used in their study.

In elaborating the item representing Justification for Knowing, most students expressed their belief that correct answers in their field were based on facts or concrete evidence. Our prior study [1], conducted with the same population, supported the uneven proportion of students who favored evidence-based justification. Among the 101 participants in that study [1], 71 of them disagreed with the statement: "Correct answers in this field are more a matter of opinion than fact," while only 16 participants agreed. With respect to researchers' intended meaning, higher ratings (agreement) in this subscale represent more constructivist views; however, perhaps this interpretation is not appropriate with engineering students. In engineering language, according to participants, "opinion" is not a positive word, and they connected opinions with personal bias and bad consequences. "Fact" was viewed as evidence, which they believed was the key component of the success in engineering designs.

In reference to Item 12, "Correct answers in this field are more a matter of opinion than fact" under the subscale of Justification for Knowing, students stated that they had to be very certain about what they are doing within their field. However, they tended to believe that knowledge in their field was evolving and agreed with Item 23, "Answers to questions in this field change as experts gather more information" under the subscale of Certainty of Knowledge. Our prior study [1] showed that 85 out of 101 participants agreed with the statement in Item 23 compared to 10 participants who disagreed with 6 of them choosing neutral; 56 out of 101 disagreed with Item 12 compared to 23 who agreed with 22 choosing neutral. That is saying, while most participants agreed with Item 23 , they tended to disagree with Item 12, even though the two items use the same word "answers" to refer to knowledge in the field and should be positively correlated. A possible reason might be students understand the word "answers" in the two items differently. The "answers" in Item 12 means knowledge directly related to practices, while the item for Certainty of Knowledge, refers to theories or methods, which represent knowledge that guides their practices. The failure to differentiate the different forms of engineering knowledge could lead to misrepresentations of students' beliefs and confound the interpretations of results. To increase the validity of the items, researchers must find appropriate words to describe the forms of engineering knowledge that they intend to measure. As Lederman and his colleagues [20] discussed in their study, individuals typically see increments of certainty from hypotheses, to theories, to laws. Thus, students' beliefs regarding scientific knowledge are related to their perception of the certainty of a specific kind of knowledge. When engineering students talk about 'answers to the questions in the field,' they themselves are not aware of the differences between forms of scientific knowledge. Thus, these items should be rephrased to better target the intended meaning according to specific research intentions.

The findings of this study add to the evidence regarding the confounding interpretation of the mid-point of a Likert scale, particularly when the ratings represent opposite poles of a construct. In this study, students chose the neutral stance for various reasons. For example, in the item for Source of Knowledge, students chose neutral because they used a situational strategy to accept the professor's knowledge in the beginning, and then, when they had more time after class, they figured out the knowledge for themselves. This seems like a mix of both naïve and 
sophisticated beliefs whereby students believe what the professor says is truth, yet they also believe that knowledge should be constructed by themselves. Similar to Muis et al.'s [12] study, when students encounter conflicting examples for an item, they tend to choose neutral as their response. For example, a student who chose neutral for the item under Certainty of Knowledge stated that, "we pretty much know how to build bridges now, and the field is not going to go ... further until we have hovering bridges. But [in] some fields, like biomedical engineering, things are changing all of the time, very rapidly." One thing to note is the choice of a neutral point might be an indication of students' awareness of context related to their beliefs. Students who chose a neutral stance for the item of Source of Knowledge explained that whether or not they accept answers from experts depended on which experts they had in mind. They wanted to evaluate the experts first, and then make the judgement of the validity of the expert's answers. As mentioned above, the student who put neutral for the item of Certainty of Knowledge made a comparison between two different fields (civil engineering vs. biomedical engineering) and was aware that her beliefs would vary according to the different fields. Contrary to theory, these students' choices of neutral points might reflect a more sophisticated thinking than other students who stick to the ratings of the scales.

\section{Conclusion}

The measurement validity issues with the self-report instruments of domain-specific epistemic beliefs may be due to any of the reasons we described in section " 2.2 Psychometric issues in current instruments," or a combination of the reasons. Our study explored these possible explanations by adopting the approach of cognitive validity interviewing in terms of how engineering students interpret the survey items about engineering-specific epistemic beliefs. The cognitive validity scores suggested that most of the items were interpreted within an acceptable range, except for the item in the subscale of Simplicity of Knowledge. However, acceptable cognitive validity doesn't mean good statistical validity or reliability. The findings from our analysis identified ways that the measurement validity of engineering students' epistemic beliefs measures might be improved. In addition to re-conceptualizing the subscale of Simplicity of Knowledge, researchers need to re-phrase the items to better accommodate students' beliefs within the context of engineering fields. Furthermore, researchers should be cautious about using a neutral point in measuring students' stances about their beliefs because they might have various interpretations about the neutral point that significantly undermine the validity of the self-report instrument. Overall, our results provide a starting point for creating better items to assess engineering students' epistemic beliefs. 
Reference

[1] J. Chen and J. E. Turner, "Epistemological beliefs of engineering students," presented at $40^{\text {th }}$ Annual Conference on Eastern Educational Research Association, 2017, Richmond, VA. 2017.

[2] M. Schommer, "Effects of beliefs about the nature of knowledge on comprehension," Journal of Educational Psychology, vol. 82, pp. 498-504, Sep. 1990.

[3] B. K. Hofer, "Dimensionality and disciplinary differences in personal epistemology," Contemporary Education Psychology, vol. 25, pp. 378-405, Oct. 2000.

[4] P. Wood and C. Kardash, "Critical elements in the design and analysis of studies of epistemology," in Personal Epistemology: The Psychology of Beliefs about Knowledge and Knowing, B. K. Hofer and P. R. Pintrich, Ed. Mahwah, NJ: Erlbaum, 2002, pp. 231-260.

[5] G. Schraw, L. D. Bendixen, and M. E. Dunke, "Development and validation of the epistemic belief inventory," in Personal Epistemology: The Psychology of Beliefs about Knowledge and Knowing, B. K. Hofer and P. R. Pintrich, Ed. Mahwah, NJ: Erlbaum, 2002, pp. 261-275.

[6] W. G. Perry, Forms of Intellectual and Ethical Development in the College Years: A Scheme. New York: Holt, Rinehart, and Winston, 1970.

[7] B. White, A. Elby, J. Frederiksen, and C. Schwarz, "The epistemological beliefs assessment for physical science," presented at Annual Conference on American Education Research Association, 1999, Montreal, Québec, Canada, 1999.

[8] G. Qian and D. Alyermann, "Role of epistemological beliefs and learned helplessness in secondary school students' learning science concepts from text," Journal of Educational Psychology, vol. 87, pp. 282-292, May. 1995.

[9] C. Faber and L. C. Benson, "Engineering Students' Epistemic Cognition in the Context of Problem Solving," J. Eng. Educ., vol. 106, pp. 677-709, Oct. 2017.

[10] C. Geraldine, E. Jan, L. Lieve, and B. Hadewych, “Assessing epistemological beliefs: Schommer's questionnaire revisited," Educational Research and Evaluation: An International Journal on Theory and Practice, vol. 7, no. 1, pp. 53-77, Mar. 2001.

[11] W. A. Sandoval, "Understanding students' practical epistemologies and their influence on learning through inquiry," Sci. Ed., vol. 89, pp. 634-656, June. 2005.

[12] K. R. Muis, M. C. Duffy, G. Trevors, J. Ranellucci, and M. Foy "What were they thinking? Using cognitive interviewing to examine the validity of self-reported epistemic beliefs," International Education Research, vol. 2, pp. 17-32, Mar. 2014. 
[13] J. A. Greene and S. B. Yu, "Modeling and measuring epistemic cognition: A qualitative reinvestigation," Contemporary Educational Psychology, vol. 39, no. 1, pp. 12-28, Jan. 2014.

[14] J. Leach, R. Millar, J. Ryder, and M. G. S'er'e, "Epistemological understanding in science learning: The consistency of representations across contexts," Learning and Instruction, vol. 10, pp. 497-527, Dec. 2000.

[15] W. A. Sandoval and K. Morisson, "High school students' ideas about theories and theory change after a biological inquiry unit," Journal of Research in Science Teaching, vol. 40, no. 4, pp. 369-392, Mar. 2003.

[16] S. A. Karabenick, M. E. Woolley, J. M. Friedel, B. V. Ammon, J. Blazevski, C. R. Bonney, and K. L. Kelly, "Cognitive processing of self-report items in educational research: Do they think what we mean?" Educational Psychologist, vol. 42, no. 3, pp. 139-151, Dec. 2007.

[17] W. R. Shadish, T. D. Cook, and D. T. Campbell, Experimental and Quasi-Experimental Designs for Generalized Causal Inference, 2nd ed. Boston: Houghton-Mifflin, 2002.

[18] G. Guest, A. Bunce, and L. Johnson, "How many interviews are enough?: An experiment with data saturation and variability," Field Methods, vol. 18, no. 1, pp. 59-82, Jan. 2006.

[19] J. W. Creswell, Qualitative Inquiry and Research Design: Choosing Among Five Approaches, 4th ed. CA: Thousand Oaks, Sage, 2013.

[20] N. G. Lederman, F. Abd-El-Khalick, R. L. Bell, and R. S. Schwartz, "Views of nature of science questionnaire: Toward valid and meaningful assessment of learners' conceptions of nature of science," Journal of Research in Science Teaching, vol. 39, no. 6, pp. 497521, July. 2002. 